\title{
Aflatoxin Contamination in Foods and Foodstuffs
}

\author{
Setsuko TABATA* \\ 田端 節子*：食品のアフラトキシン污染
}

Aflatoxin, a metabolic product of Aspergillus flavus and A. parasiticus, is one of the strongest carcinogenic compounds, and it is found in several kinds of foods and foodstuffs ${ }^{1,2)}$. Most countries set limits on aflatoxins, and the regulation level in Japan is $10 \mathrm{ppb}$ for aflatoxin $\mathrm{B}_{1}$. In our laboratory, aflatoxins in foods and foodstuffs have been tested since 1971, when aflatoxin was first found in peanut cream in Japan. This report summarizes the data on aflatoxin contamination in commercial foods and foodstuffs in Tokyo for 15 years during the period of 1982-1996.

\section{Materials and Methods}

Samples A total of 7,500 samples, consisting of nuts, cereals, spices, beans, and dairy products, collected from commercial markets and from the food industry in Tokyo, were examined.

Aflatoxins determination Aflatoxins were determined and confirmed by the method reported earlier ${ }^{3)}$, as follows : 200-1000 g samples were ground; after addition of water, aflatoxins were extracted with chloroform from $20 \mathrm{~g}$ of the ground sample, purified by florisil column chromatography, and determined and confirmed by high-performance thin-layer chromatography. Detection limits (ppb) were 0.2 for $B_{1}, 0.1$ for $B_{2}, 0.2$ for $G_{1}, 0.1$ for $G_{2}$, and 0.1 for $M_{1}$. Recoveries of aflatoxins were $91 \%$ for $B_{1}, 89 \%$ for $B_{2}, 78 \%$ for $G_{1}, 78 \%$ for $G_{2}$, and $92 \%$ for $M_{1}$.

\section{Results and Discussion}

Aflatoxins in nuts Measurable levels of aflatoxins were found in peanut, pistachio nut, Brazil nut, and sesame seed (Table 1).

Of 459 samples of peanut examined, 35 samples were contaminated with aflatoxins. 3 samples contained over $10 \mathrm{ppb}$ aflatoxin $\mathrm{B}_{1}$, the regulation level in Japan. The high incidence in peanut was from certain kinds of their products such as peanut butter and peanut powder. The incidence of aflatoxin in whole peanut, the largest part of the peanut sample, was low, but high in crushed, powdered peanut, peanut paste, and peanut oil (Table 2). The reasons were probably as follows. One possible reason was that the whole peanut products were higher grade, and crushed peanuts, whose grade the consumer cannot estimate, were lower grade. The other possible reason was that aflatoxin contamination is very partial, grain by grain. In the case of crushed peanut product, a large amount of peanuts were crushed. Therefore, the probability to include aflatoxin-contaminated grain was high.

* 東京都立衛生研究所（广169-0073 東京都新宿区百人町 3-24-1）

The Tokyo Metropolitan Research Laboratory of Public Health (3-24-1, Hyakunin-cho, Sinjuku-ku, Tokyo 169-0073, Japan) 
Table 1 Incidence and levels of aflatoxins in nuts and nut products

\begin{tabular}{lrccccc}
\hline \hline \multirow{2}{*}{ Sample } & \multirow{2}{*}{$\begin{array}{c}\text { No. of } \\
\text { sample }\end{array}$} & No. of & \multicolumn{5}{c}{ Range (ppb) } \\
\cline { 3 - 7 } & positive & $\mathrm{AFB}_{1}$ & $\mathrm{AFB}_{2}$ & $\mathrm{AFG}_{1}$ & $\mathrm{AFG}_{2}$ \\
\hline Peanut & 459 & $35(3)$ & $0.4-21.7$ & $0.1-5.3$ & $0.3-22.1$ & $\mathrm{Tr} .-6.8$ \\
Pistachio nut & 481 & $9(7)$ & $0.8-1382$ & $0.1-260$ & 306 & 48.3 \\
Cashew nut & 212 & 0 & & & & \\
Almond & 151 & 0 & & & & \\
Brazil nut & 8 & $1(1)$ & 10.2 & 0.8 & 3.2 & 0.3 \\
Walnut & 71 & 0 & & & & \\
Macadamia nut & 20 & 0 & & & & \\
Pine seed & 17 & 0 & & & & \\
Pumpkin seed & 23 & 0 & & & & \\
Mixed nut & 17 & 0 & & & & \\
Sesame seed & 47 & 5 & $0.6-2.4$ & $0.2-0.5$ & & \\
Others & 101 & 0 & & & & \\
\hline Total & 1607 & 50 & & & & \\
\hline
\end{tabular}

( ) : No. over regulatory limit $\operatorname{Tr} .:<0.1 \mathrm{ppb}$

Table 2 Incidence of aflatoxins in peanut and peanut products

\begin{tabular}{lccc}
\hline \hline \multicolumn{1}{c}{ Sample } & No. of sample & No. of positive & Incidence of $\mathrm{AFB}_{1}(\%)$ \\
\hline Whole & 391 & $1(1)$ & 3 \\
Crushed & 7 & $2(1)$ & 29 \\
Powdered & 17 & $11(1)$ & 64 \\
Paste & 34 & 16 & 47 \\
Oil & 11 & 5 & 45 \\
Total & 459 & 35 & 8 \\
\hline & & \multicolumn{2}{c}{ ( ) $:$ No. over regulatory limit }
\end{tabular}

Of 481 samples of pistachio nut examined, 9 were contaminated with aflatoxins, and 7 samples contained over $10 \mathrm{ppb}$ aflatoxin $\mathrm{B}_{1}$ (Table 1 ). The level of aflatoxin in pistachio nut was very high ; the highest level of aflatoxin $\mathrm{B}_{1}$ was $1382 \mathrm{ppb}$. The tested samples were from Iran and the United States. A great difference was observed in the incidence and level of aflatoxins depending on the country of origin. Of the positive samples, only 1 sample was from the United States. The other 8 samples were from lran, although more than half of the samples tested was from the United States. This difference was probably due to different conditions after harvest.

One of the 8 brazil-nut samples contained over $10 \mathrm{ppb}$ aflatoxin $B_{1}$. The sample was from Brazil.

Of 47 samples of sesame seed examined, 5 contained aflatoxins. Most of the positive samples were from China.

No aflatoxins were detected from cashew nut, almond, or walnut, although they were imported from India, the United States, and China, areas suitable for producing aflatoxins.

Aflatoxins in cereals and sugars Measurable levels of aflatoxins were found in coix seed, corn, buckwheat, and sugar (Table 3 ).

The positive sample of rice was powdered rice, called "shiratama-ko" in Japan. 
Table 3 Incidence and levels of aflatoxins in cereals, sugar, and their products

\begin{tabular}{|c|c|c|c|c|c|c|}
\hline \multirow{2}{*}{ Sample } & \multirow{2}{*}{$\begin{array}{l}\text { No. of } \\
\text { sample }\end{array}$} & \multirow{2}{*}{$\begin{array}{l}\text { No. of } \\
\text { positive }\end{array}$} & \multicolumn{4}{|c|}{ Range (ppb) } \\
\hline & & & $\mathrm{AFB}_{1}$ & $\mathrm{AFB}_{2}$ & $\mathrm{AFG}_{1}$ & $\mathrm{AFG}_{2}$ \\
\hline Rice & 170 & 1 & 0.5 & & & \\
\hline Wheat & 352 & 0 & & & & \\
\hline Barley & 276 & 0 & & & & \\
\hline Oat & 39 & 0 & & & & \\
\hline Rye & 21 & 0 & & & & \\
\hline Coix seed & 212 & $48(1)$ & $0.1-14.9$ & Tr. -1.8 & $0.3-0.7$ & \\
\hline Corn & 474 & 4 & $0.1-0.4$ & & & \\
\hline Buckwheat & 252 & 23 & $0.1-8.8$ & $0.1-0.9$ & $0.2-0.8$ & Tr. -0.1 \\
\hline Mixed flour & 81 & 0 & & & & \\
\hline Sugar & 31 & 12 & $1.0-1.5$ & $0.1-0.2$ & & \\
\hline Others & 78 & 1 & 0.4 & & & \\
\hline Total & 1991 & 92 & & & & \\
\hline
\end{tabular}

Coix seed is a traditional herbal medicine. During 1980s, it was in great demand as a healthy food in Japan, and a large amount of coix seed was imported from other Asian countries. Over $20 \%$ of samples examined were contaminated with aflatoxins. 1 sample contained over $10 \mathrm{ppb}$ aflatoxin $B_{1}$. The positive samples were imported from Thailand.

Aflatoxin $B_{1}$ was found at levels of $0.1-0.4 \mathrm{ppb}$ in 4 of 474 corn samples examined. Of the positive samples, 2 were corn grits and 2 were corn snacks. We reasoned that the source of aflatoxin might be corn grits.

Of 252 buckwheat samples examined, 23 were contaminated with aflatoxins. The highest level of aflatoxin $B_{1}$ was $8.8 \mathrm{ppb}$, near the regulatory limit in Japan. All the positive samples were buckwheat powder, packed $200-300 \mathrm{~g}$ in small paper bags, and sold at supermarkets for cooking at home. Buckwheat is a staple food in Japan, used in foods such as buckwheat noodles, and intake is large. Therefore, if commercial buckwheat noodles were contaminated with aflatoxins, it would be a serious problem. So we started to examine commercial buckwheat noodles. No aflatoxin was detected. We believe that the buckwheat powder contaminated with aflatoxin was on a different commercial route.

Of 31 sugars examined, 12 were contaminated with aflatoxins. All of the positive samples were mucovado (crude sugar) from the extreme south of Japan. No aflatoxin was detected in refined sugar.

Aflatoxins in Spices Measurable levels of aflatoxins were found in white pepper, red pepper, paprika, nutmeg, and mixed spice (Table 4).

Of 220 white pepper samples examined, 21 were contaminated with aflatoxins. The level of aflatoxin $\mathrm{B}_{1}$ was $0.1-2.3 \mathrm{ppb}$, which was not very high.

A high incidence (38\%) and high levels of aflatoxins were found in red pepper. 3 samples imported from China contained over $10 \mathrm{ppb}$ aflatoxin $\mathrm{B}_{1}$.

Over $50 \%$ of paprika samples examined were contaminated with aflatoxins. Some of them were imported from Spain. 
Table 4 Incidence and levels of aflatoxins in spices

\begin{tabular}{|c|c|c|c|c|c|c|}
\hline \multirow{2}{*}{ Sample } & \multirow{2}{*}{$\begin{array}{l}\text { No. of } \\
\text { sample }\end{array}$} & \multirow{2}{*}{$\begin{array}{l}\text { No. of } \\
\text { positive }\end{array}$} & \multicolumn{4}{|c|}{ Range (ppb) } \\
\hline & & & $\mathrm{AFB}_{1}$ & $\mathrm{AFB}_{2}$ & $\mathrm{AFG}_{1}$ & $\mathrm{AFG}_{2}$ \\
\hline Black pepper & 120 & 0 & & & & \\
\hline White pepper & 220 & 21 & $0.1-2.3$ & $0.1-0.3$ & & \\
\hline Red pepper & 81 & $31(3)$ & $0.2-27.7$ & $0.1-1.2$ & $0.1-2.1$ & $0.1-0.2$ \\
\hline Paprika & 44 & 26 & $0.2-6.5$ & $0.1-0.3$ & & \\
\hline Nutmeg & 257 & $155(17)$ & $0.2-60.3$ & $0.1-6.5$ & $0.1-15.8$ & $0.1-0.4$ \\
\hline Mace & 56 & 0 & & & & \\
\hline Caraway & 21 & 0 & & & & \\
\hline Thyme & 25 & 0 & & & & \\
\hline Cinnamon & 18 & 0 & & & & \\
\hline Coriander & 13 & 0 & & & & \\
\hline Laurel & 23 & 0 & & & & \\
\hline Clove & 18 & 0 & & & & \\
\hline Hop & 52 & 0 & & & & \\
\hline Ginger & 22 & 0 & & & & \\
\hline Sage & 27 & 0 & & & & \\
\hline Curry powder & 18 & 0 & & & & \\
\hline Mixed spice & 161 & 28 & $0.2-1.9$ & & & \\
\hline Others & 128 & 0 & & & & \\
\hline Total & 1304 & 261 & & & & \\
\hline
\end{tabular}

Table 5 Incidence and levels of aflatoxins in beans and bean products

\begin{tabular}{|c|c|c|c|c|c|c|}
\hline \multirow{2}{*}{ Sample } & \multirow{2}{*}{$\begin{array}{l}\text { No. of } \\
\text { sample }\end{array}$} & \multirow{2}{*}{$\begin{array}{l}\text { No. of } \\
\text { positive }\end{array}$} & \multicolumn{4}{|c|}{ Range (ppb) } \\
\hline & & & $\mathrm{AFB}_{1}$ & $\mathrm{AFB}_{2}$ & $\mathrm{AFG}_{1}$ & $\mathrm{AFG}_{2}$ \\
\hline Soy bean & 113 & 0 & & & & \\
\hline Beans for beanjam & 916 & $14(4)$ & $0.1-254$ & $0.4-8.5$ & & \\
\hline Coffee bean & 77 & 0 & & & & \\
\hline Others & 100 & 0 & & & & \\
\hline Total & 1206 & 14 & & & & \\
\hline
\end{tabular}

The highest incidence and levels of aflatoxins were found in nutmeg. 17 samples contained over $10 \mathrm{ppb}$ aflatoxin $B_{1}$. Most of them were imported from Indonesia.

No aflatoxins were detected in black pepper, mace, or laurel.

A remarkable difference was found in the incidence and level of aflatoxins between white and black pepper, and between nutmeg and mace, although they are a part of the same plant.

There are two possible reasons. One is the difference in the treatment after harvest. To make white pepper, the pepper is soaked in filthy ponds to remove the skin at the producing district, in a tropical area. The other reason seemed to be the difference between the spices as substrates for aflatoxin producing fungi.

Aflatoxins in beans $0.1-254 \mathrm{ppb}$ of aflatoxin $\mathrm{B}_{1}$ was found in beans for bean jam, which are called butter bean and which come from Myanmar (Table 5). Aflatoxin was also detected in 
bean jam, the product of the butter bean.

No aflatoxins were detected in soybean, coffee bean, cacao bean, or other beans.

Aflatoxins in dairy foods Of 354 samples of natural cheese examined, 44 contained 0.1-1.2 ppb of aflatoxin $\mathrm{M}_{1}$. No aflatoxins were detected in processed cheese, or other dairy foods.

Aflatoxins in other foods No aflatoxins were detected in dried fruit, tea, herbs, meat, eggs or other foods.

Annual change in aflatoxin contamination The contamination of aflatoxin in foods was not constant during the 15-year period (Fig. 1).

The incidence of aflatoxin in natural cheese and buckwheat was high in 1982-1985. After 1985 , no aflatoxins were detected in these foods. Aflatoxin $M_{1}$ in dairy food is a metabolite of aflatoxin $B_{1}$ in dairy cattle. Therefore, these results indicated that aflatoxin contamination in feed for dairy cattle decreased after 1985. The reason for this seems to be that the number of countries with legislation controlling aflatoxin in feedstuffs increased from 22 in 1981 to 35 in 1986. Also, the European Community directive was tightened in 1984 when the tolerance for aflatoxin $B_{1}$ in feedstuffs for dairy cattle was reduced from 20 to $10 \mathrm{ppb}$. The reason for the change in buckwheat was probably that buckwheat from Brazil was not imported after 1986.

Until 1992, the incidence of aflatoxins in white pepper was over $30 \%$, but no aflatoxins have been detected in recent years.

A high incidence was found in nutmeg throughout the period, reaching over $80 \%$ during $1985-$ 1990.

The constant incidence in peanut was due to peanut butter.

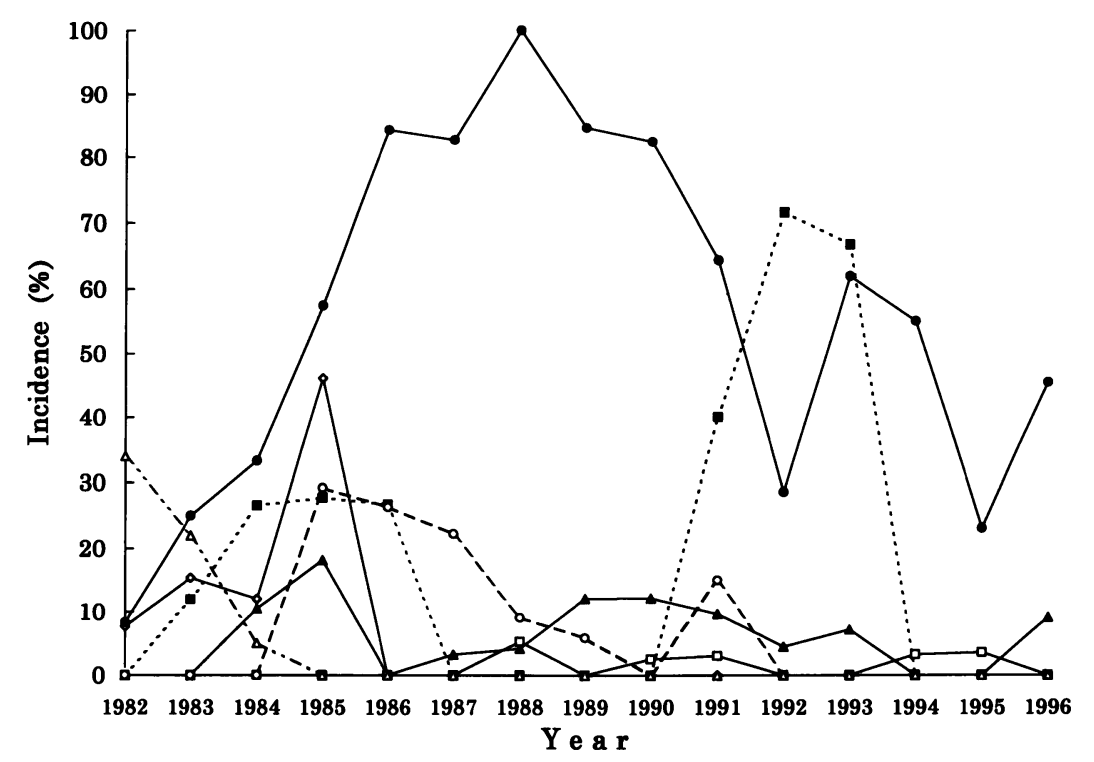

Fig. 1 Change in incidence of aflatoxin

$\triangle$ Natural cheese, $\neg$ Buckwheet, - - - - White pepper, $\longrightarrow$ Nutmeg,
$\longrightarrow$ Peanut, 


\section{Conclusion}

Aflatoxins are found in several kinds of foods and foodstuffs every year, and some of them contain over $10 \mathrm{ppb}$ aflatoxin $\mathrm{B}_{1}$, the regulatory limit in Japan. Also most aflatoxins in foods remained after cooking, and ingested by humans ${ }^{4}$. Therefore, it is important to develop a method for preventing aflatoxin contamination, and to check carefully for aflatoxins in foods and foodstuffs. We must try to eliminate aflatoxin-contaminated foods, to reduce the risk of aflatoxins.

\section{References}

1) Tabata, S., Kamimura, H., Tamura, Y., Yasuda, K., Ushiyama, H., Hashimoto, H., Nishijima, M. and Nishima, T.: J. Food Hyg. Soc. Jpn. 28, 395 (1987)

2) Tabata, S., Kamimura, H., Ibe, A., Hashimoto, H., Iida, M., Tamura, Y., and Nishima, T. J. A. O. A. C. Int. 76, 32 (1993)

3) Kamimura, H., Nishijima, M., Yasuda, K., Ushiyama, H., Tabata, S., and Matsumoto, S. : J. A. O. A. C. 68, 458 (1985)

4) Tabata, S., Kamimura, H., Ibe, A., Hashimoto, H., Tamura, Y., and Nishima, T. : J. Food Hyg. Soc. Jpn. 33, 150 (1992) 